\title{
Problems of ensuring the competitiveness of the region in the conditions of COVID-19
}

\author{
Vadim Pashkus ${ }^{1, *}$, Anna Volkova $^{2}$, and Yulia Maltseva ${ }^{3}$ \\ ${ }^{1}$ Saint Petersburg State University, Faculty of Economics, Department of Economics \& Economic \\ Policy, University embankment 7-9, 199034, St Petersburg, Russia \\ ${ }^{2}$ Saint Petersburg State University, Faculty of Economics, Department of Political Governance, \\ University embankment 7-9, 199034, St Petersburg, Russia \\ ${ }^{3}$ Saint Petersburg State University, Faculty of Economics, Department of Cultural Studies, Philosophy \\ of Culture and Aesthetics, University embankment 7-9, 199034, St Petersburg, Russia
}

\begin{abstract}
Research background: In the context of the COVID-19 pandemic and its global consequences, a fundamentally different economic environment arises, which requires the use of new approaches to the formation of the economic policy of the region and the identification of new ways to ensure the global competitiveness of the region. Territories are beginning to compete for previously unclaimed resources, as well as use new methods of promotion and positioning.

Purpose of the article: The purpose of this work is to identify new economic conditions caused by the COVID-19 pandemic and its consequences, as well as to assess the impact of these conditions on the effectiveness of the economic policy of the region and the applied promotion and positioning strategy.

Methods: The methods of this study are determined by the increasing level of uncertainty of regional development processes, which requires the adaptation of analysis tools. The work uses matrix and hierarchical research methods that allow for a qualitative analysis of problem situations.

Findings \& Value added: The research carried out made it possible to identify and systematize the main characteristics of the new economic environment and assess its impact on the applied development strategy of the region, which guarantees a higher probability of achieving strategic competitiveness. The novelty of the study lies also in the recognition of the mobilization effect of "forced digitalization", while in the context of a pandemic, this mobilization was based on stable (stereotypical) interaction practices.
\end{abstract}

Keywords: Global Tourism Industry, global competitiveness of the country. digitalization, institutional designs, "coercive digitalization".

JEL Classification: $L 83, L 52, M 31$

\footnotetext{
*Corresponding author: v.pashkus@spbu.ru
} 


\section{Introduction}

During the period of the impact of the COVID-19 pandemic on all global economic processes, the world tourism industry is experiencing the strongest impact. Traveling in the conditions of the pandemic has become very difficult and quite expensive, which makes people refuse not only to travel abroad, but even inside their own country. As a result, travel companies around the world suffer huge losses, which they try to compensate for at the expense of those few who are not afraid of the difficulties of new travel. There is a new round of price growth with spontaneously arising stricter rules of movement for tourists who are still going to take a trip in new conditions, which causes a further reduction in the tourist flow.

Another serious problem of travel during the pandemic is associated with a high level of dynamics of travel conditions. Countries can spontaneously open or close the movement of tourists for each other, which is sometimes associated with a variety of factors, the prediction of which is almost impossible. Moreover, among the factors of influence are not only those that arise due to the pandemic, but also political or economic factors masquerading as them. For example, this is the problem of mutual recognition of vaccines and, consequently, certificates of vaccination. Often this problem arises precisely for political and even economic reasons. All the countries that hold their vaccines are very jealous of other countries that hold them. It would seem that the considerations of achieving the common interests of eradicating the virus or at least neutralizing it to the level of a seasonal disease that does not have a global spread require joint efforts. However, in fact, serious clashes are taking place in the vaccine market, some participants of this market, who have captured a certain segment of the global market, do not want to let other vaccines go there, even when this is fraught with an aggravation of the epidemiological situation. Countries resell to each other, and sometimes openly impose vaccines that are not popular due to the presence of serious health threats and an abundance of serious side effects. As a result of all this struggle, new obstacles are emerging for the global recognition of vaccines and the restoration of tourist flows. One of the ways to answer this challenge is to activate domestic tourism.

The tourist business and air carriers do not want to bear the risks of non-departure of tourists associated with a possible illness of the latter, as well as with changes in the rules of stay of tourists in another country or another region and the inability of tourists to comply with them. Thus, they shift these financial risks to the tourists themselves, for whom the trip becomes simply unaffordable. And the more tourists face the problem of non-repayment of funds for previously purchased vouchers, air tickets or other tourist products, the lower the image of tourist operators and air carriers falls. Also, the image of those countries and regions that refused tourists to stay, could not provide them with the promised range of services, or provided them at much higher prices than previously announced, suffers even more. All this irritates tourists, who already had to pay dearly for the trip, often at least 2-3 times more expensive than a similar trip before the pandemic, especially when it comes to international travel. But even regions of one country with high demand due to the lack of alternatives often strive to get the most out of such a situation. This eventually leads to an increase in the cost of traveling around the country, and, consequently, the discontent of tourists, especially if the level of service stated in the offer does not correspond to the real one.

However, in relation to individual countries or regions, tourists are ready to put up with difficulties and high costs, even if the rest provided to them did not fully correspond to the declared one. And in relation to other countries and regions, the level of trust is much lower. In general, it can be stated that, first of all, the number of tourists who can be classified as travelers has decreased in the world. This is due to the high complexity of organizing routes during the pandemic and the increasing costs for them, as well as the complexity of the conditions of stay in other regions and countries. All this leads to the fact that tourists prefer to limit themselves to rest with a minimum level of additional travel. Residents of cold 
regions tend to visit accessible countries or regions with a warmer climate and the presence of the sea or other comfortable places of rest. Residents of hot regions tend to go to cooler ones, although usually only a slight decrease in temperature to the comfort level is allowed. An important factor for tourists is the requirements for wearing masks indoors and outdoors, the need to provide vaccination certificates, PCR tests and their number during the trip and at the end of it. It is these factors that ensure the comfort of vacationers and the additional costs that they have to endure to get the opportunity to relax in this region or country.

Tourist operators also strive to work only with the most stable destinations, giving preference to domestic tourism, which is most controlled in terms of stability. When working with foreign destinations, the emphasis is mainly on recreation, and the offers themselves are significantly overpriced. However, there are quite a few problems with regard to domestic tourism. So, the presence of high demand for domestic tourism, especially to the regions most attractive for a comfortable stay from the point of view of the residents of this country, unfortunately, is not always properly supported by the offer, and sometimes this offer takes the strangest forms. In some cases, the offers are frankly overpriced in the absence of a developed infrastructure and a service corresponding to the price and the needs of tourists. Moreover, the result of such market behavior is a negative reaction of tourists, which moves from specific unseemly tourist offers to those places where the tourist had a chance to rest, and to the image of the entire domestic tourism as a whole. Moreover, due to the fact that a tourist acts in accordance with the concepts of modern marketing as a part-time marketer at the same time, and in two markets at once, namely, the tourist market and the territory market, his opinion is transmitted to potential tourists and consumers of the place's services, negatively affects the image of the place and undermines its brand.

The saddest thing is that the undermining of the prestige of domestic tourism has a negative impact on the global image of the place and related tourist offers. As the experience of countries that are attractive for domestic tourism and are highly appreciated by their citizens shows, their high appreciation of local attractions and the conditions for visiting them has a positive impact on their global attractiveness. (Pashkus et al., 2021) However, this applies to tourism in its broad sense, excluding highly specialized areas of tourism, such as, for example, religious tourism. The attractiveness of places of religious worship of the local population may not be so high for foreign tourists or foreign tourists come to these places for other purposes. For example, domestic tourism is very developed in India, but the targets of domestic and external tourists often differ very much. If you do not take into account these differences, you can not only weaken the impressions of tourists from the place, but also cause them a strong negative reaction. Due to the fact that the image is the sum of all the impressions that accumulate in a certain collective consciousness, negative perceptions give rise to stereotypes that will be very difficult to fight in the future. The unwillingness of the regions to conduct an active advertising campaign to promote domestic tourism on the Internet also affects, which has become particularly important in the conditions of pandemic restrictions. Digital designs of regional-level structures are mainly poorly focused on the development of communication skills, on participation and do not contribute much to the breakthrough positioning of the tourism sector and the unique opportunities of the regions.

Thus, there are several regions in Russia that are highly attractive from the point of view of tourism development, but have a contradictory perception, both in the domestic and foreign tourist market. One of these regions is the Caucasus, in particular, Dagestan, Kabardino-Balkaria, Karachay-Cherkessia, Chechnya. Some of these regions have formed a frankly negative image around themselves, for example, Dagestan and Chechnya, which is connected with their recently very turbulent political situation in the regions that have received wide worldwide publicity. Many domestic and especially foreign tourists are scared off by the recent political instability in these regions, frequent acts of violence and complex relations. Moreover, potential tourists were stopped by the lack of free access to objective 
information about the situation in the region. The lack of information that potential tourists could learn directly from primary sources that they could trust, gave rise to new fears and doubts.

Despite the fact that the section "Tourism" is presented on the website of the Head of the Republic of Chechnya (http://chechnya.gov.ru/) in the second-level masonry in the "Republic" section, the information there is quite formal and is updated with a delay of more than six months. It declares that in order to develop the tourism sector, 2020 has been declared the "Year of Tourism" in the Chechen Republic, it is stated that the Republic's main tasks for the year are related to increasing the pace of development of the tourism sector, increasing tourism potential and solving problematic issues, but there are no specific programs, plans or reports. The digital design of the Ministry of Tourism of the Chechen Republic can be described in a similar way (https://chechentourism.ru/).

The tourist portal of the Chechen Republic Visit Chechnya (https://visitchechnya.ru/), on the contrary, is a good example of how in the process of institutionalization of digital innovations, when the exchange of knowledge and technologies becomes vital for the development of each firm, industry, national or regional economies, and the pluralization of the digital space makes strict regulation ineffective, an attitude is formed to ensure coordination to a greater extent than regulation (Volkova and Kulakova, 2021). This confirms the persistence of this trend even in systems where knowledge management and socioinformation processes are based exclusively on traditional, conservative principles and values. The portal is available in four languages, including English and Arabic. The portal presents an interactive map of the republic, thematic tourist routes, an up-to-date calendar of events and an online tour booking system.

At the same time, it is necessary to pay tribute to the fact that the right choice of the target audience can significantly correct the situation. Thus, a significant part of potential tourists are really afraid to go to regions characterized by a difficult political and economic situation. And these are mainly tourists who are focused on a relaxing holiday in places with developed infrastructure. However, there is a significant cluster of tourists, mainly young people who are not burdened with young children, and active, often athletic, middle-aged and sometimes even older people, without children or with adult children, who are ready to sacrifice a certain level of comfort for new unexpected impressions, new experiences and the opportunity to see something otherwise inaccessible or very expensive when visiting in another way. A significant part of this target group is not so important to have a developed infrastructure, they are not afraid of the contradictory past of the territory, especially if there are no problems at the moment or they do not capture tourists. Moreover, the presence of a contradictory image and previously existing problems of access to the territory, on the contrary, provokes this category of tourists to visit the region. In fact, this is the case that Dominic Medway and Gary Warnaby call demarketing (they clearly emphasize the negative, not the positive in a particular place) or "dark place marketing" (Medway and Warnaby, 2008), for example, the tour "Terrible Weekend at the Russian Special Forces University" is aimed at this target group, positioned as "The most atmospheric tour in the Chechen Republic, which is in the top among many sophisticated tourists" (https://visitchechnya.ru/tours/tour/groznyevyhodnye-2). Some of this category of tourists previously focused on foreign trips, often selforganized. This category of tourists is not used to paying too much, is quite active, is able to find the necessary options for itself, and strives to experience interesting adventures on a trip. If there is no possibility of traveling abroad or if the price of visiting foreign territories is unreasonably high, they would be ready to visit new and little-known regions of their country. This category of tourists is more likely to visit less accessible, less well-known, but unusual places. But for this category of tourists, the role of available information about the current situation becomes even more significant. 
At the same time, the regions of the Caucasus are conducting a very strange policy in the tourism sector. On the one hand, the regions and their population are very interested in the influx of tourists, but, on the other hand, they strongly oppose the arrival of professionals in the regions who would be able to form a high-quality tourism infrastructure. Thus, preventing the penetration of potential competitors into the region, they are not able to bring tourism in the region to a new level of quality. Moreover, by not allowing major players in the tourist market, local travel companies themselves compete fiercely with each other and are often inclined to lose a tourist themselves, but not give a competitor the opportunity to earn. At the same time, local agencies do not have access to potential consumers, and the methods of promotion they use are ineffective. The information that they seek to convey to potential tourists either does not reach them in principle, or causes distrust on the part of tourists.

A potential tourist does not receive the necessary information about tourism opportunities in a timely manner, cannot independently build a route, has difficulties getting information about the sights that he could visit, travel opportunities in the region, the availability of public transport. The most desperate tourists still get to the region, but even within the region, as a rule, they cannot contact agencies that organize tours within the region or carry out trips to neighboring regions. People often find out about the presence of individual attractions or interesting natural places absolutely by chance, but even if there is a desire to visit a place that they have learned about, they often face the fact that they do not know how to get to it. Tourists with their own cars have certain advantages. However, they do not know the local roads, do not always have driving skills in the mountains, they are afraid for the safety of their car on local roads or the behavior of local residents towards their cars.

In some regions of the Caucasus, the situation is better, for example, in KarachayCherkessia, tourism in the region is best developed, but basically all trips are tied to Kislovodsk, where there are many vacationers coming to mineral springs, or are concentrated around Dombay, as the most famous ski resort. Here, on the spot, a tourist can find a variety of offers for visiting the sights of the region or neighboring regions of the Caucasus. In Kabardino-Balkaria, such a center of attraction for tourism is Terskol, from where you can make trainings from two existing lifts to Cheget and Elbrus or to the Elbrus Nature Reserve, and local hotels, as a rule, organize transfers and offer individual car trips within the region. In Dagestan and Chechnya, the situation is even more complicated. There, even on the spot, a tourist often cannot get information about how to get to the place of interest to him. Basically, these are taxis and minibuses, the mode of which can be unstable, and finding the right vehicle is difficult even in the absence of a language barrier.

A tourist experiences difficulties with finding transport, often can not find places of public catering or he is not satisfied with the price category of establishments or the quality and assortment of food. Not in all regions it is possible to buy the necessary products, since mainly small shops are represented, the range of which is very limited, or the main trade is conducted only in the market, which may work irregularly. The disadvantage for modern tourists is also the weak distribution of payment terminals and non-cash payment means, which are used only by some hotels and individual shops. Basically, cash payment prevails. Many tourists from large regions, who are used to the applepay, googlepay and even facepay systems, react negatively to the need to constantly carry cash, take all payment cards with them, and often the inability to use credit cards for payment. Thus, the actual price of the trip increases due to the use of an inconvenient payment method for the tourist.

A similar situation, only even more complicated, is developing with inbound tourism. In addition to all the problems described above, a foreign tourist also experiences language difficulties. He cannot call a taxi on his own, agree on the route, price and agree on other issues that require the understanding of the parties. The lack of regular transport routes marked on the map, shops and restaurants operating on a clear schedule, the difficulty of obtaining information about attractions, all this becomes simply insurmountable for them. 
Only a few foreign tourists still decide on such a trip. Now, during the pandemic, even for very desperate tourists, going to such regions becomes almost impossible.

At the same time, it should be noted that the contradictory image of the regions for a certain category of foreign tourists, on the contrary, adds a special flair to the place. In this sense, the policy of Russia itself attracts foreign tourists, since a trip to the regions of Russia with a contradictory image turns into a quest for survival, and the traveler himself becomes a hero in his own eyes. Many tourists go to remote corners of the world for these feelings, experience life far from civilization, overcome difficulties bordering on real danger, although they still want to be convinced that nothing really terrible will happen to them. Often their expectations have nothing to do with reality, precisely because they do not know how to really assess the level of danger, although new potential tourists of this category of danger, to which past tourists were exposed, are not stopped, but only egged on. Thus, what repels the classic target groups, new groups of extreme people only attract.

Indeed, in the Alps, you can be exposed to no less risk than in the Caucasus, as well as find in the Caucasus an equally convenient and pleasant place of rest, which does not require mastery of extreme mountaineering skills to achieve it and is not inferior in beauty and variety of opportunities to many European resorts. But potential foreign tourists rest, first of all, on the problem of information asymmetry. They do not receive information about what they can find in this region, which forces them to turn to other countries and regions that are more widely covered through various channels.

The" forced digitalization " of the pandemic period prompted the creation and promotion of various resources offering virtual tours of the republics of the Caucasus. So, for example, today high-quality virtual tours in Ingushetia and Chechnya are possible. Such resources not only contribute to the adaptation of citizens to the conditions of the isolation regime, but also can stimulate interest in visiting these Russian regions in the future and work not only to develop the image of these Caucasian territories, but also to form and improve their image as progressive digital spaces. Moreover, digital positioning is based on such traditional values as hospitality and family well-being, loyalty to national traditions, security, and trust. This is supported by slogans and headlines on websites, visuals and musical accompaniment.

\section{Methodology}

To assess the competitive potential of territories, we use a composite method that includes strategic analysis tools (a modified McKinsey matrix), hierarchical analysis methods (a modified MAI procedure) and methods for constructing marginal replacement coefficients of particular evaluation criteria. (Pashkus and Pashkus, 2011; Pashkus et al., 2018) Using a modified MAI procedure, we obtain normalized weight coefficients that allow positioning the selected regions on the corresponding competitive plane. The applicability of these procedures for the global tourism market has been considered by us earlier. However, due to the pandemic, we will consider regions with mainly domestic tourism.

We will assess the competitive potential of the selected Caucasian regions for domestic tourists. Due to the fact that the most developed center of tourism in the North Caucasus region is Kislovodsk and Dombay, which belong to the Stavropol Territory, we will also include this region in the analysis. In addition, it is in the Stavrapol region that there are two air hubs (Mineralnye Vody and Nalchik) and the largest railway stations, from where it is convenient to get to places of interest to tourists. The analysis will be carried out using the competitiveness matrix modified by the authors, on the horizontal axis of which the competitive status of the region is postponed, and on the vertical axis - its attractiveness for the development of tourism. The results of the analysis are shown in the figure 1. 
Tourist competitiveness of the territory

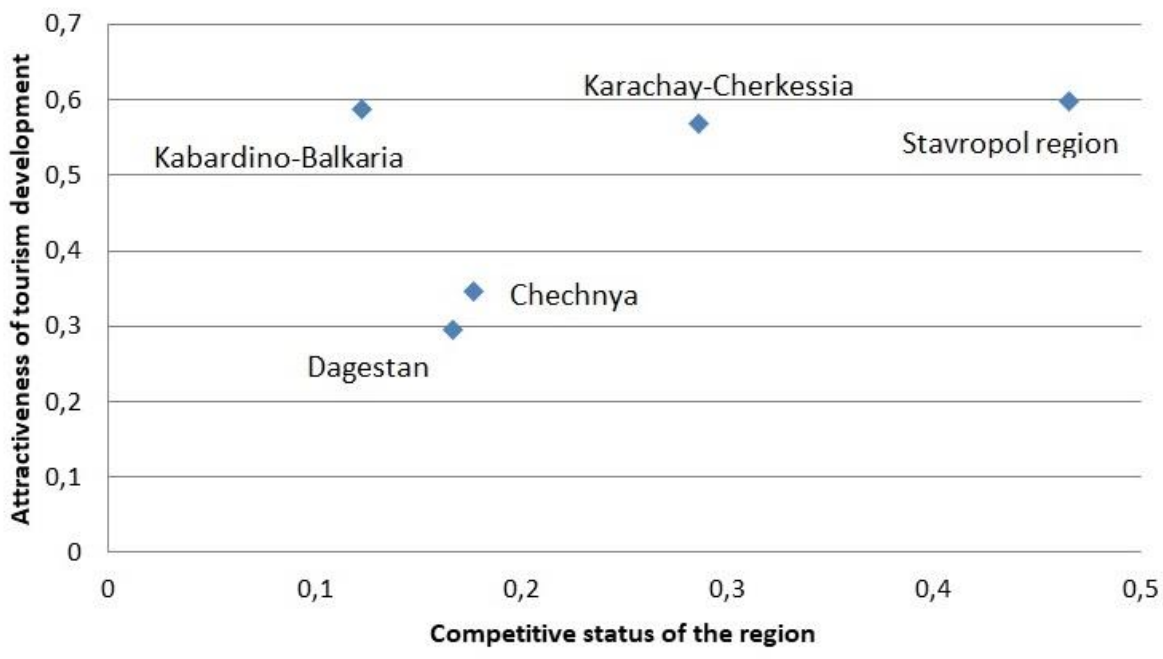

Figure 1. Competitive positioning of the North Caucasus regions.

\section{Results}

As a result of the analysis, it turned out that the absolute leader among other North Caucasian regions is the Stavropol Territory, on the territory of which tourism began to develop first and from which trips to other regions are carried out. Moreover, it is this region that has established brands of places, such as Kislovodsk and Mineralnye Vody. In the domestic Russian tourist market, these brands are already quite stable and loyalty to them is quite high. At the same time, it should be noted that if we consider the Stavropol Territory in comparison with other, more tourist-developed regions, for example, the Krasnodar Territory or the Crimea, then its position should significantly weaken. In this competitive group, the region should maintain and maintain its potential and expand the directions of its information representation in all available information environments and social networks.

Karachay-Cherkessia is the No. 2 winner solely due to the greater coverage from the tourist companies of the Stavropol Territory and the presence of a developed domestic brand of the Dombay ski resort. The region needs to develop and strengthen its competitive identity, expand the map of branded places that are attractive to tourists. It is especially important for the region to develop its competitive status, in particular, through information coverage of the tourist attractiveness of the region, as well as the use of a positive assessment of the region by loyal tourists.

Kabardino-Balkaria is in the intermediate category No. 1, that is, it has a high potential, but the competitive status even in the Russian market is still very low. This region, with the skillful development of infrastructure and proper information support, is able to become a leader. And, we must pay tribute, now the near Elbrus region is actively developing.

Chechnya and Dagestan were in the intermediate category No. 2, that is, the most average position. This position is dangerous because all investors are afraid to invest in projects that correspond to this position, since their results can be very unreliable. Unfortunately, this position is very unstable, so for all its attractiveness, only short-term and most profitable events are implemented here. Tours to the regions are organized, but they often have an 
inflated price for the tourist, do not have the proper quality or do not allow the tourist to fully get to know and love this region.

\section{Discussion}

The methodology presented in the article can be applied both to the assessment of the competitiveness of regions, and for a comparative analysis of different regions in different countries of the world when assessing their global competitiveness. However, the widespread use of this technique entails certain problems.

So, the studied regions should have more or less similar indicators, otherwise either the result is known in advance (and will be trivial), or it is necessary to complicate the methodology by introducing additional procedures there. The same applies to the data error.(Starobinskaya, 2019)

Actively implemented protectionist measures, the development of domestic tourism are applied by many countries (Aliaskarova et al., 2020; Fajgelbaum et al., 2020) change the competitiveness indicator and require certain amendments to the methodology.

In fact, the role of the brand, including the cultural brand, is not considered when analyzing the competitive position. This is partly due to the fact that these regions do not have a very stable positive image, and the attractiveness of negative sides (as a number of authors advise us (Torres, 2012; Medway and Warnaby, 2008) for such regions rather repels potential tourists. It can be assumed that today the brand makes it possible to obtain stable competitive advantages and significantly increase the competitiveness of the territory. (Kotler and Gertner, 2002; Foroudi P. et al., 2016), the brand will also allow building a new identity, moving away from focusing exclusively on a strategic perspective and uniting various stakeholders (including residents) on its basis (Kavaratzis and Hatch, 2013; Braun et al., 2013; Parker et al., 2015).

It should be noted that attempts to promote the regions are carried out within the framework of standard schemes. (Zhang et al., 2018; Pashkus et al. 2019) It cannot be said that these approaches do not work: the "unforgettable image" of the North Caucasus is very attractive and the corresponding positive images have already developed. But, nevertheless, to get the best result, it requires the help of the state and the involvement of teams of specialists who could promote various types of tourism from creative and ecotourism, to the joint use of tourist products (Kostkova, 2020; Hollowell et al., 2019)

For the development of the brand, it is necessary to pay great attention to the problems of digitalization. The creation and development of the necessary resources, the opportunity to get the necessary information allows you to create a primary interest and form a positive (or, if this is required, for example, a niche strategy - a negative image) of the place. (Balandina et al., 2020; Volkova and Kulakova, 2021)

And, finally, this model does not take into account the "possession effect", when the value of "one's" resource is overestimated, which leads to incorrect strategic decisions and incorrect economic policy priorities, which have a pronounced populist aspect. (Hartzmark et al., 2021; Liang and Xiaosheng, 2020; Rodrik, 2018)

\section{Conclusion}

As the analysis showed, from the point of view of tourism, the North Caucasus region is in the process of formation. This applies to both fairly well-promoted regions and regions that are little known even to domestic consumers. To change the situation, the state will need huge efforts to support and promote the competitive status of the regions. 
And digitalization will play a huge role in this. Indeed, the pandemic has changed social and cultural life, giving it a "digital impulse". The rejection of major cultural and sports events of the federal scale, the fading and transformation of cultural life and the need to abandon the usual tourist routes and the usual communication, poses a threat to the social climate, the social well-being of the country, but also encourages new, innovative and unexpected forms of interaction. Using the example of the tourism sector, it is also obvious that the success of implementing the digitalization policy depends on building a system of state and non-state entities that use common norms and values that interact with each other on the basis of resource interdependence in order to achieve a common, public good.

Digitalization will push the development of territories, will allow us to focus on intangible assets, primarily regional brands. Therefore, the increase in the competitiveness of the regions of the North Caucasus can be associated not only with the creation of a regional tourism infrastructure (which is actively being done now), but also with the active actions of the state to promote the brands of the territories. The development of the brand (and ideallya strong brand) of the territory will allow it to compensate for potential investments by attracting various groups of tourists and in the long - term perspective-to increase the global competitiveness of the region.

\section{Acknowledgements}

The research was made with the financial support of the Russian Science Foundation 19-1800210 "Political ontology of digitalization: a study of the institutional basis of digital formats of state governability"

\section{References}

1. Aliaskarova, Z., Pashkus, V., Blagikh, I.A. (2020). Proactive Industrial Policy as the Main Strategy for Improving Russia's Competitiveness in the Context of Global Economic Processes. SHS Web of Conferences, 74, 06002.

2. Balandina, D.M., Aliaskarova, Z.A., \& Ignatova, A.M. (2020). Digital economy: developmental characteristics and consumer behavior. Izvestia of the International Academy of Agrarian Education, 52, 59-63.

3. Braun, E., Kavaratzis, M., \& Zenker, S. (2013). My City - My Brand: The Role of Residents in Place Branding. Journal of Place Management and Development, 6 (1), 18 28.

4. Fajgelbaum, P.D, Goldberg, P., Kennedy, P.J., \& Khandelwal, A. (2020). The Return to Protectionism. The Quarterly Journal of Economics, 135 (1), 1-55.

5. Foroudi, P., Gupta, S., Kitchen, P.J., \& Foroudi, M. M. (2016). A framework of place branding, place image, and placereputation: Antecedents and moderators. Qualitative Market Research: An International Journal, 19(2). 241-264.

6. Hartzmark, S.M., Hirshman, S.D., \& Imas, A. (2021). Ownership, Learning, and Beliefs. The Quarterly Journal of Economics, 136(3), 1665-1717.

7. Hollowell, J. C., Rowland Z., Kliestik T., Kliestikova, J., \& Dengov, V.V. (2019). Customer Loyalty in the Sharing Economy Platforms: How Digital Personal Reputation and Feedback Systems Facilitate Interaction and Trust between Strangers. Journal of Self-Governance and Management Economics, 7(1), 13-18.

8. Kavaratzis, M., \& Hatch, M.J. (2013). The dynamics of place branding: an identity-based approach to place branding Theory. Marketing Theory, 13(1), 69-86. 
9. Kostková, M. (2020). Shared accommodation as a globalization trend in tourism. SHS Web of Conferences, 74, 03002.

10. Kotler, P., \& Gertner, D. (2002). Country as brand, product, and beyond: a place marketing and brand management perspective. Journal of Brand Management, 9 (4-5), 249-261.

11. Liang, A., \& Xiaosheng, M. (2020). Complementary Information and Learning Traps. The Quarterly Journal of Economics, 135 (1), 389-448.

12. Medway, D., \& Warnaby, G. (2008). Alternative perspectives on marketing and the place brand. European Journal of Marketing, 42(5/6), 641-653.

13. Parker, C., Roper, S., \& Medway, D. (2015). Back to basics in the marketing of place: The impact of litter upon place attitudes. Journal of Marketing Management, 31(9-10), $1-23$.

14. Pashkus, M., Pashkus, V., \& Koltsova, A. (2021). Impact of Strong Global Brands of Cultural Institutions on the Effective Development of Regions in the Context of the COVID-19 Pandemic. SHS Web of Conferences, 92, 01039.

15. Pashkus, V. Y., \& Pashkus, N. A. (2011). Algorithmization of matrix tools of strategic analysis and approaches to their application in the non-profit sector of the economy. Strategic Management, 3, 200-218.

16. Pashkus, V., Pashkus, N. \& Pashkus, M. (2018). Strategic Positioning of Territories in the Global Economy: Brand Development in Accordance with the Matrix of Competitiveness of Territories. Globalization and its Socio-Economic Consequences. 18th International Scientific Conference Proceedings. Zilina, Rajecke Teplice, Slovak Republic, 2727-2734.

17. Pashkus, N.A., Pashkus, V.Y., Altunyan, A.G., Protasov, A.Y. \& Maltseva, Y.M. (2019). Cultural City Brands and Global Competitiveness. Revista San Gregorio, 36, 197-209.

18. Rodrik, D. (2018). Populism and the economics of globalization. Journal of International Business Policy, 1, 12-33.

19. Starobinskaya, N.M. (ed.) (2019). Socio-cultural sphere in the new economy: from the development of education to the art market. St. Petersburg: KultInformPress.

20. Torres, I. (2012). Branding slums: a community driven strategy for urban inclusion in Rio de Janeiro. Journal of Place Management and Development, 5(3), 198 - 211.

21. Volkova, A.V., \& Kulakova, T.A. (2021). Network, procedural and cognitive components of digital public governance implementation designs: European countries experience. Vestnik of Saint Petersburg University. Philosophy and Conflict Studies, 37 (1), 118-135.

22. Zhang, H., Wu Y., \& Buhalis, D. (2018). A model of perceived image, memorable tourism experiences and revisit intention. Journal of Destination Marketing \& Management, 8, 326-336. 